\title{
COVID-19 Compared with Other Viral Diseases: Novelties, Progress, and Challenges
}

\author{
Lidong Wang ${ }^{1 \star}$, Cheryl Ann Alexander ${ }^{2}$
}

\author{
${ }^{1}$ Mississippi State University, Mississippi, USA \\ ${ }^{2}$ Institute for IT Innovation and Smart Health, Mississippi, USA \\ *Corresponding Author: lidong@iser.msstate.edu
}

Citation: Wang L, Alexander CA. COVID-19 Compared with Other Viral Diseases: Novelties, Progress, and Challenges. Electron J Gen Med. 2021;18(1):em265. https://doi.org/10.29333/ejgm/8575

\section{ARTICLE INFO}

Received: 5 Jun. 2020

Accepted: 4 Aug. 2020

\begin{abstract}
COVID-19 is a newly discovered, highly infectious disease and has rapidly spread into at least 213 countries as a pandemic. This paper is a comprehensive review article of COVID-19 and four other viral diseases, including influenza, Severe Acute Respiratory Syndrome (SARS), Middle East Respiratory Syndrome (MERS), and Ebola virus disease (EVD). The cause of COVID-19 is the novel coronavirus-SARS-CoV-2. The transmission of COVID-19 is complex and rapid; therefore, it is difficult to control the spread of the disease. Certified specific antiviral drugs are slowly becoming available for COVID-19, although a few treatments such as Remdesivir, hydroxychloroquine, dexamethasone, and therapeutic plasma exchange (TPE) have been found somewhat effective. Effective vaccines are still in the process of development and several countries, including the USA are conducting Phase 3 trials currently to fast-track the vaccines. All these issues have created significant challenges in reducing the morbidity and mortality of this global infectious disease. COVID-19 has led to vast impacts on public health and the global economy. With economic shutdowns, social distancing, increased handwashing, and sanitizing have been first line therapies for mitigating the spread of COVID-19 and have created a new normal. COVID-19 is different from influenza and previous pandemic diseases, such as SARS, MERS, and EVD, but has some similarities to them. Influenza and these pandemic diseases are introduced in this paper as a comparison with COVID-19. The features of COVID-19, progress achieved in treatment, emerging technologies in testing and diagnosis, and current and future challenges are presented. Specifically, topics regarding COVID-19 in this paper cover basic facts, the questionable origin of COVID-19, testing and diagnosis, pharmaceutical treatment and comfort measures, strategies and management for fighting against COVID-19, and the emotional, psychological, and mental health impacts of shelter-in-place orders and quarantine of COVID-19.
\end{abstract}

Keywords: COVID-19, SARS-CoV-2, coronavirus, SARS, MERS, Ebola, acute respiratory distress syndrome, influenza

\section{INTRODUCTION}

Influenza A (H1N1) pdm09 (pH1N1) surfaced in Canada and Mexico in March 2009. It is a strain of influenza A H1N1 resulting from a combination of pig, bird, and human influenza viruses. Patients who have influenza and develop pneumonia, may require mechanical ventilation and are at a high risk of rapid progression to Acute Respiratory Distress Syndrome (ARDS), which causes life-threatening hypoxemia [1]. ARDS is an immune-driven pathology that has been observed in cases such as Severe Acute Respiratory Syndrome coronavirus (SARS-CoV) infection, MERS, EVD, and COVID-19 [2]. After a pandemic due to the influenza A virus, a zoonotic coronavirus was detected in the Middle East in 2012. The Middle East Respiratory Syndrome coronavirus (MERS-CoV) causes severe respiratory disease (e.g., pneumonia) with more than 35\% mortality. The onset of MERS in humans is characterized by cough and high fever $\left(\geq 38^{\circ} \mathrm{C}\right)$. SARS-CoV and MERS-CoV can result in symptoms ranging from asymptomatic cases to ARDS and respiratory failure $[2,3]$.
Ebola viral disease (EVD) resulting from the Ebola viruses (EBOVs) is a severe and acute illness with a rate of mortality from $25 \%$ to $90 \%$ according to records from the World Health Organization (WHO) [4]. EVD has primarily occurred in West and Sub-Saharan Africa since it emerged in 1976; however, other countries, including the USA, have experienced outbreaks caused by travelers from Africa. The most potential vaccine and therapeutic target for the EBOV infection is the envelope glycoprotein (GP). GP coordinates viral-host membrane fusion [5] although the successful implementation of a vaccine has yet to occur. EBOV can cause similar symptoms to those of COVID19 including micro-clots, cytokine storm (which is typically the cause of more severe and fatal cases), and thromboembolisms.

The deficiency of clinical research responses to pandemic influenza, SARS, MERS, and EBOV indicates that available research models cannot sufficiently improve the quality of public health or clinical care. Suggestions have been made for improvement, but models and computations still fail to predict outcomes adequately or correctly. First, data or sample collection requirements for clinical and public health decisionmaking should be integrated within a unified framework that 
combines a risk-based (not a discipline-based) approach to ethical review and consent. Second, clinical research methods and related tools should be developed to meet epidemiological and contextual challenges of epidemic or infectious diseases [6]. Third, investigator-led clinical research networks that are primed and incentivized in response to the outbreak of diseases should be funded or sponsored [6].

Severe Acute Respiratory Syndrome Coronavirus 2 (SARSCoV-2, previously called 2019- $\mathrm{nCoV}$ ) is the causative pathogen of Coronavirus Disease 2019 (COVID-19) and has quickly circulated in the world [7] with hotspots in the USA, Italy, Brazil, Spain, Russia, etc. and covered more than 213 countries with sick patients, depleting critical medical supplies and beds in the world's intensive care units (ICUs). The basic reproduction number $R_{0}$ of COVID-19 is estimated to be around 2.2, which means each patient averagely spreads the disease to 2.2 people [8]. However, the Centers for Disease Control (CDC) in the USA report the data more so as infecting 5-8 individuals per sick individual. Patient Zero (PZ) is the first person who is infected with a new virus or bacterial disease and therefore becomes the carrier of the virus or disease in an outbreak. It is significant to find $\mathrm{PZ}$ in an outbreak because knowing where the person has been and who have been in contact with helps researchers and physicians better track, understand, and control the virus or disease infection. The PZ of COVID-19 has not been found [9]. Governmental health officials have stated that contact tracing (i.e., tracking sick individuals who test positive and testing anyone in contact with the person), is essential to control of the viral outbreaks plaguing the world.

After the COVID-19 outbreak in Wuhan City, China, the cruise ship, Diamond Princess, was quarantined on February 3 , 2020 because a passenger tested positive for COVID-19. The passenger disembarked in Hong Kong before the test and diagnosis [9]. Approximately 355 cases were confirmed as positive for COVID-19 infection on the Diamond Princess by February 16,2020 . It was important to predict the reproductive number $R_{0}$ of the new virus on the cruise ship in the early stage of the outbreak and estimate daily new cases. It was calculated that the median with $95 \%$ confidence interval of $R_{0}$ of COVID19 was approximately 2.28 on the cruise ship in the early stage. It was critical to reduce the $R_{0}$ to control daily cases and the outbreak [10]. This relies on not only medical science and technology, but also strategies and management.

The Division of General Surgery at the University of Washington in Seattle, USA designed and implemented an emergency restructuring of the facility's general surgery resident care teams to comply with physical distancing requirements recommended by the Presidential experts, optimized workforce well-being, and continued excellent patient care during the COVID-19 outbreak. This is a successful example in management during the pandemic. An approach to general surgery resident allocation by dividing patient care into separate inpatient care, operating care, and clinical care teams was introduced. Surgical resident team restructuring is critical during a pandemic to optimize patient care and ensure the well-being and vitality of the resident workforce while guaranteeing the whole workforce is not compromised. The number of surgery residents with direct patient contact was limited and independent resident physician teams were created and isolated from each other to create physical distancing [11].

The main purpose of this paper is to introduce COVID-19 and SARS-CoV-2. Four other viral diseases, including influenza,
SARS, MERS, and EVD are also introduced for a comparison with COVID-19. The features and novelties of COVID-19, progress in treatment, emerging technologies, and challenges in fighting COVID-19 are presented. The following is the arrangement of the rest of the paper: the second section presents methods and literature research results; the third section introduces influenza; the fourth section presents SARS and MERS; the fifth section describes EVD; the sixth section deals with SARS-CoV-2 and COVID-19; and the final section is discussions and conclusion.

\section{METHODS}

As we have mentioned, this paper primarily deals with COVID-19 and SARS-CoV-2. However, in the early stage of this disease, many people were not aware of its substantial risk partly due to some similarities to other viral diseases such as SARS, MERS, EVD, and even influenza. The pathogen itself which caused the virus was named SARS-CoV-2 (like SARS-CoV, i.e., SARS-CoV-1) and was also called 2019 novel coronavirus (2019-nCoV). People have understood more about its distinct features since its outbreak, especially since becoming a virulent global pandemic. Therefore, four other viral diseases (influenza, SARS, MERS, and EVD) are also addressed in this paper to compare with COVID-19. Not only similarities, but also distinct differences of the features of COVID-19 are identified and disclosed.

Literature research was performed on the database EBSCO via 'Advanced Search' to research COVID-19 and the four other viral diseases. Papers published between December 2019 and May 2020 in English and in scholarly (peer reviewed) journals were considered. For COVID-19, 'Subject Terms' was selected as 'Field' to search papers. The Subject Terms include COVID19, SARS-CoV-2, Novel Coronavirus, 2019-nCoV, and nCoV. Duplicated papers were removed. A total of 253 papers that matched the topics of this paper were selected for the literature review to better understand COVID-19, including its causes, transmission and epidemiology, diagnosis, transmission prevention and control, etc. For the four other viral diseases, 'Title' was selected as 'Field' to narrow the range of papers because these viral diseases were only used in comparison with COVID-19. The terms used in 'Title' were influenza, SARS, MERS, and EBOLA, respectively. After duplicated papers were excluded, 106 papers were selected for the literature review because the papers matched the topics of this paper and were appropriate for the comparison with COVID-19.

It should be noted that many professional journals implemented the fast review and fast publication policy for manuscripts regarding COVID-19 and SARS-CoV-2 during this critical time of the COVID-19 pandemic. The review and publication process of some manuscripts took a short time (one or two weeks) and their methods and results are somewhat weak; therefore, among papers published before May 2020, only quality papers were cited in this paper. Totally, 64 papers were cited in this paper.

\section{INFLUENZA}

Influenza or "the flu" is one of the main causes of respiratory illness and complications among adults, the 
Table 1. Differences between the common cold and influenza

\begin{tabular}{lll}
\hline Aspects & Common Cold & Influenza \\
\hline Body temperature & usually slightly elevated & high $\left(>38^{\circ} \mathrm{C}\right)$ \\
\hline Headache & rare & very common \\
\hline Dry cough & rare & common \\
\hline Sore throat & common & rare \\
\hline Rhinorrhea & very common & common \\
\hline Hoarseness & common & rare \\
\hline Osteoarticular pain & rare, mild & very common, severe \\
\hline Lack of appetite & rare & common \\
\hline General wellbeing & moderately bad & very bad \\
\hline Disease onset & slow, with mild & sudden, with acute \\
& symptoms & symptoms \\
\hline
\end{tabular}

elderly, and children of all ages. Like COVID-19, the influenza virus tends to affect the weak, elderly, and those in high-stress environments. Immunizing children with an inactivated influenza vaccine does not reduce all causes of respiratory illness episodes which occur in primary care during an influenza epidemic period [12]. Parents' awareness of recommendations regarding children's influenza vaccines is low. Healthcare providers' vaccine endorsement is key and healthcare professionals, especially general practitioners and pediatric specialists ought to be urged to talk about influenza vaccines with parents [13].

Influenza is an acute infectious disease of viral etiology. It can cause serious complications, such as myocarditis, pneumonia, inflammation of kidneys, and death. Vaccination is the most useful approach to avoiding the influenza infection. Influenza is different from the common cold, which is shown in Table 1 [14].

Seasonal influenza, along with pneumonia is one of the USA CDC's top ten causes of death in the world. Simulation is a timely and cost-effective approach to forecasting the infection evolution based on the coupling influence of various aspects, such as an individual's features, current and previous vaccinations, travel patterns, interaction patterns, and meteorological conditions. A meteorological model was developed to evaluate effects of changes in relative humidity and temperature on epidemic influenza patterns. It was shown that a $10 \%$ reduction in relative humidity leads to an increase of around $1.6 \%$ in the rate of final infection. The effect due to temperature changes on the spread of infection is detectablea $1.1 \%$ decrease in the infection spread per extra degree of temperature [15].

Influenza A ( $\mathrm{H} 1 \mathrm{~N} 1)$ pdm09 is the influenza A virus in its pandemic form and has a highly mutant, transmissible, and lethal capacity. This virus threatens the world population with a high mortality rate [16]. Transmission from human to human through air droplets or sometimes from pigs to humans. The influenza virus has multiple different RNA segments, which can reassemble to make new virus strains (i.e., mutations) with the possibility to infect an unimmunized individual, thus causing another outbreak. Gene reassortment is a process through which new strains are emerging in pigs as they have specific receptors for both human influenza and avian influenza viruses [17]. The presence of dyspnea, hypertension, thoracic pain, diabetes mellitus, or an abnormal chest radiography or computed tomography on admission were associated with worse clinical outcomes for patients with the infection of the H1N1 virus. Therefore, using readily accessible clinical and imaging features for admission should help evaluate patients with the H1N1 infection [18].
A chest X-ray is non-specific for H1N1 virus-associated pneumonia. High-resolution computed tomography (HRCT) can improve the diagnosis and follow-up of pneumonia associated with the H1N1 virus. HRCT can recognize small lesions, which permits a prompt diagnosis and treatment after imaging. HRCT is the best imaging technique to display lung changes in various phases of pneumonia [16]. Molecular combination with nanotechnology provides new and effective diagnostic methods. There are some biosensors specific for influenza A (H1N1) pdm09 detection [17].

\section{SARS AND MERS}

Coronaviruses (CoVs) mainly cause enzootic infections in mammals and birds. Infections crossed over to humans as well in recent decades. The outbreaks of SARS and MERS have confirmed the fatality of CoVs when they cross the barrier of species and infect humans. CoVs cause diseases with various degrees of symptoms, ranging from upper respiratory tract infections (e.g., the common cold) to lower respiratory tract infections, such as pneumonia, bronchitis, ARDS, etc. [19]. SARS and MERS have demonstrated the potential to cause massive nosocomial outbreaks. Transmission trees can provide details regarding epidemiological links between cases, draw attention to the duration of a disease outbreak, and help identify super-spreaders. Targeted vaccination strategies could be explored based on the stochastic simulation and transmission trees associated with nosocomial outbreaks of MERS and SARS [20].

SARS-CoV emerged from coronavirus circulation in Asian animal markets in 2002 and 2003. The emergence of the virus caused a global outbreak of a respiratory disease with a $10 \%$ mortality rate [2]. It has been regarded by the WHO that SARS$\mathrm{CoV}$ is perhaps from bats. Hallmark clinical symptoms after a SARS infection is a high fever (i.e., > 38 degrees $\mathrm{C}$ ) and acute lung inflammation resulting in ARDS and severe hypoxemia, requiring mechanical ventilation [21]. Viroporins, viral proteins with ion channel (IC) activity that play a considerable role in viral replication and pathogenesis, are found in RNA viruses, and interact with various cellular membranes and lipids to stimulate virus reproduction. SARS-CoV encodes three viroporins (proteins $3 \mathrm{a}, \mathrm{E}$, and $8 \mathrm{a}$ ) while most other CoVs only encode one viroporin. The full-length $E$ and 3a proteins are necessary for maximal SARS-CoV replication and virulence; however, viroporin 8a has only a slight impact on the activities. Viroporins $E$ and $3 a$ of SARS-CoV are necessary for efficient replication in vitro and in vivo. The viral viroporins and PDZbinding motif (PBM) are appropriate targets for antiviral therapy and mutation in attenuated SARS-CoV vaccines [22]. The pathology of SARS-CoV is like that of SARS-CoV-2. MERS also causes a similar inflammatory process which affects the lungs and other organs.

MERS-CoV can cause an especially fatal respiratory infection affecting the inflammatory markers of the lungs. The first MERS-CoV infection case occurred in Saudi Arabia in June 2012. MERS-CoV then spread to some adjacent countries (mainly Jordan and Qatar) and imported cases of this virus and disease were reported in Africa, Europe, Asia, and the Americas. MERS-CoV has been dangerous to human health in the world since 2012 and cases have occurred in 27 other countries (e.g., Qatar, Tunisia, Jordan, Italy, Germany, France, and United Kingdom) [23, 24]. Clinical characteristics of the MERS-CoV vary 
widely, from the absence of symptoms ( $14 \%$ to $80 \%$ of cases) to the flu-like syndrome, pneumonia, and ARDS. The three most common symptoms are cough, fever, chest pain, and dyspnea [24]. Patients with severe acute respiratory illness due to the MERS-CoV infection have symptoms, such as fever, cough, diarrhea, shortness of breath, nausea/vomiting, fatal pneumonia, and kidney infection in the most severe forms. The incubation period of MERS-CoV is around five to six days with a fatality rate of up to $30 \%$ to $40 \%$ [23]. Most people with MERS have progressive and worse outcomes, such as severe pneumonia, extra pulmonary organ dysfunction, and ultimately death [25].

MERS-CoV is a zoonotic virus and it is caused by a single stranded and positive $(+)$ sense RNA beta-coronavirus that is a pathogen of zoonotic reservoirs. The origin of MERS-CoV is not completely known; however, MERS-CoV is believed to originate in bats and then transmit to humans from dromedary camels according to the analysis of various virus genomes [23,25,26]. Large MERS-CoV outbreaks have repetitively had destructive impacts on healthcare systems and settings. Sporadic community cases are still being reported. A small and consistent proportion of MERS cases have no camel exposure. Constant epidemiologic and virologic monitoring is needed to find other exposures that cause virus transmission. Human cases with MERS-CoV result from primary or secondary transmission. Primary transmission is defined as zoonotic transmission from camels or an unidentified source, while secondary transmission is due to contact with a MERS patient [26].

SARS-CoV and MERS-CoV can also lead to ARDS, a reduction in the amount of lung surfactant which lubricates the lungs and make mechanical ventilation more difficult and less effective, otherwise severe, stubborn hypoxemia, ultimately results in death, or acute kidney failure, multi-system-organ failure, and septic shock [23]. One third of severe MERS patients develop pneumonia and another $20 \%$ go on to develop ARDS [24].

ARDS is an acute, diffuse, inflammatory lung injury that causes added pulmonary vascular permeability, added lung weight, and a loss of aerated tissue caused by a build-up of fluid in the alveoli. Although there have been advances in mechanical ventilation, and the treatment of ARDS, it is still related to a high morbidity rate and a mortality rate ranging from $26 \%$ to $58 \%$. Extracorporeal membrane oxygenation (ECMO) is a changed cardiopulmonary bypass circuit that acts as an artificial membrane lung and blood pump to deliver gas exchange and systemic perfusion for patients when their lungs and hearts cannot function sufficiently. ECMO is a complicated network that offers ventilation and oxygenation and permits the lungs to rest or recover from respiratory failure, while at the same time minimalizing iatrogenic ventilator-induced lung injury. ECMO has demonstrated an increased survival rate and improved outcomes of patients with severe ARDS however, ECMO is an expensive and resource-intensive system that requires trained and exceedingly skilled professionals because close and regular monitoring of the system is necessary. ARDS can be mild, moderate, or severe and although ECMO can be used as a rescue strategy if other treatment choices are not successful, it is not suggested as a main treatment for severe ARDS [27].

Although improvement has been made in the management of ARDS, the in-hospital mortality rate is still extremely high (over $40 \%$ ). Prone positioning (PP) is an effective first-line intervention for the treatment of ARDS because it increases gas exchange and reduces mortality. But the response to PP is unpredictable and can widely vary from one patient to another. Despite the difference, PP facilitates a greater survival rate among ventilated patients [28]. Patients with persistent severe ARDS have poor clinical outcomes. Identifying this kind of patients at trial enrollment can be an approach to personalized medicine [29].

\section{EBOLA VIRUS DISEASE}

Ebola Viral Disease (EVD) is a severe and overwhelmingly fatal disease [30]; death rate is approximately $80 \%$ among those infected. It is caused by the EBOV, a member of the filovirus family and occurs in humans and other primates [31]. An EBOV is a single-stranded, non-segmented, and negativesense RNA virus. EBOVs were discovered during an outbreak of EVD in the Democratic Republic of Congo in 1976 [32,33]. EVD is characterized by severe acute symptomatology, including high fevers, arthralgia, severe fatigue; hemorrhagic manifestations such as oozing and acute bleeding occur in the final stages. Life-threatening conditions such as multi-system-organ-failure and shock, ultimately leading to death [33]. EVD mortality is also increased by the "cytokine storm" like the pathology of death in COVID-19. Although the EBOV is considered to reduce clotting factors and cause seeping and oozing, it is typically the "cytokine storm" which causes death among EVD patients.

EBOVs are thought to be zoonotic; however, their original reservoir has yet to be confirmed. African fruit bats are regarded as the most likely natural reservoir for EBOVs [31,33]. Initial human infection with Ebola virus occurs through contact with an infected animal, such as a fruit bat or other non-human primate. The virus can spread from person to person via direct contact with body fluid, the blood of a symptomatic person with the EBOV infection, or a dead body of an EVD patient. Entry of body fluids (e.g., saliva, vomit, sweat, urine, feces, semen, breast milk, blood, vaginal fluid, etc.) through broken skin or mucous membranes in the nose, mouth, or eyes can cause infections [30]. With other filoviruses, EBOVs can be transmitted from an animal reservoir or intermediate host to a primary human case in a single zoonotic spillover event. The primary case then initiates the person-to-person transmission [32]. The contact situations and monitoring of infected patients as well as their families and neighbors are crucial for controlling an EVD outbreak [33].

Symptoms overlapping with other endemic diseases such as cholera, malaria, etc., have made accurate diagnosis critical and challenging. Ebola outbreaks are widespread due to the absence of sensitive, robust, rapid, and licensed diagnostic tests in remote regions where outbreaks often occur. A rapid and user-friendly diagnostic test has been established and validated. Its analytical features make it appropriate for clinical management during an EBOV outbreak in a remote region [31]. Since EBOV might stay in some body fluids after a patient recovers from the disease, EVD could continue to infect others in contact with these body fluids and result in severe epidemics again. A key priority in the fight again EVD is to develop effective vaccines against EVD. Some vaccine candidates have been assessed in clinical trials and the rVSV-EBOV vaccine is being licensed in Europe and the USA [34]. 


\section{SARS-COV-2 AND COVID-19}

\section{Basic Facts}

COVID-19 is a new infectious disease caused by SARS-CoV2 previously called 2019 novel coronavirus (2019-nCoV). COVID19 is an enveloped RNA virus, making it more susceptible to disinfectants than a regular virus. Although the infection rate is high, and COVID-19 is considered highly contagious, the mortality rate of COVID-19 is approximately $3 \%$, a relatively low mortality rate among viruses, typically affecting the elderly, those with underlying medical conditions such as diabetes, asthmas, autoimmune diseases, etc. and immunocompromised individuals, leaving the young and healthy fairly untouched, although there are many cases of disease and death in younger adults. Children seem immune or rarely infected and rarely spread the disease. COVID-19 is characterized by fever ( $>38$ degrees $\mathrm{C}$ ), body-aches, runny nose, sore throat, shortness of breath, chest pain, dry cough, and/or gastrointestinal symptoms. The most serious cases complain of chest pressure and difficulty breathing with low oxygen saturation. The virus also sheds RNA into the feces as well. COVID-19 is primarily an acute lung disease, potentially causing shortness of breath, hypoxemia, and ARDS. However, most patients with severe COVID-19 die because of a "cytokine storm," which leads to a thromboinflammatory process where there is a build-up of inflammatory markers such as interleukin (IL), tumor necrosis factor (TNF- $\alpha$ ), and other inflammatory markers, causing pneumonia and micro-clots in vessels and multi-organ dysfunction. Cardiac injury biomarkers are also increased in some patients, even those with no cardiovascular disease, resulting in death as well. This indicates a need for efficiently monitoring heart health to prevent myocarditis in patients with COVID-19. The transmission of COVID-19 is much faster than MERS and SARS. Cases of asymptomatic patients with COVID-19 have been reported [8,35-37]. Compared with the SARS-CoV infection, patients with COVID-19 have less symptoms or are completely asymptomatic yet both are still as contagious as those with the full disease. Furthermore, SARSCoV-2 causes lower respiratory tract lesions even in patients who do not have any clinical symptoms, leading to permanent lung scarring and other difficulties. Thus, some patients have the radiological evidence of pneumonia; however, they do not have a cough or fever during the infection [38]. The range of time the illness takes from onset to full-blown severe COVID-19 also varies among patients due to age, exposure, preexisting conditions, state of health, etc.

The WHO records show the period for COVID-19 from symptom onset to death is in the range of two weeks for a patient with mild symptoms up to six weeks for patients with severe symptoms, with a median of 14 days. This period relies on an individual's age and immune status [39]. The average incubation period of COVID-19 can be up to five days and the period of quarantine is 14 days starting from the last exposure date. Compared with other similar types of coronaviruses, the average time of the incubation period for COVID-19 is the longest; however, this remains argumentative because the longest incubation period for COVID-19 could be 27 days or even above [40]. Also, the origin of COVID-19 has been questionable. It has been one of people's main concerns. Although wet markets have been considered as one of the potential origins of COVID-19. And Beijing, China recently experienced an outbreak at a meat market where dozens of workers were infected, leading experts to consider the wet market as a highly likely target for the origin, although there are no bats at these wet markets.

\section{Origin of SARS-CoV-2}

It is with a high probability that SARS-CoV-2 is of a natural zoonotic origin, meaning the virus was transmitted from an animal to PZ; however, although a species of bats are thought to be responsible for transmitting the virus to humans, the role of animals in the epidemiology of SARS-CoV-2 remains primarily unknown [41]. SARS-CoV-2 is a positive-sense and single-stranded RNA virus. It has a great genetic similarity to bat coronaviruses; however, while the intermediate reservoir is thought to be pangolins, one of the most trafficked non-human mammals in Asia. But confirmation of the intermediate reservoir is yet to be made [36]. Based on genomes, the bats are the most likely origin with the intermediate reservoir most likely the pangolin [42]. The genetic analyses also predicted that bats are the most likely the source of SARS-CoV-2 though further investigation needs to confirm these facts [43].

COVID-19 is related to beta-coronavirus that infects humans and most likely mutated from a bat coronavirus into a human host. Structural analyses showed that COVID-19 was probably derived from a bat SARS-like coronavirus that had a mutation in the nucleocapsid $\mathrm{N}$ protein and the spike glycoprotein (protein S). It appears that all COVID-19 strains are similar compared to other strains associated with the same family. Thus, it has also been considered that COVID-19 resulted from some mutations of other coronaviruses. Genomic analyses do not support the idea that COVID-19 was constructed in a laboratory. To further confirm the origin of the novel virus, it is necessary to obtain the viral sequences from immediate animal sources [39].

Massive sequencing of SARS-CoV-2 strains found in humans and the CoVs of wildlife will help further evaluate the origin of the virus and propose future methods to mitigate the risk of new SARS-CoV-2 spillover incidents. Further tasks need to be implemented to handle the risk of future pandemics due to CoVs: 1) research on CoV-host interactions to be conducted both in vivo and in vitro; 2) development of new anticoronaviral medicines and assessment of their efficacy in animal models and cell cultures; and 3) deterrence of the animal-to-human infection through a more friendly environment management and a ban of wet markets [41].

\section{Transmission and Spread of SARS-CoV-2 and COVID-19}

SARS-CoV-2 primarily share the mode of transmission with MERS-CoV and SARS-CoV because it spreads largely through droplet or respiratory secretions. Saliva is a biofluid mainly generated from salivary glands in the oral cavity and has been reported SARS-CoV-2 nucleic acid positive in some cases. Besides lungs, tongues and salivary glands are possibly additional hosts of SARS-CoV-2 because of the expression of angiotensin-converting enzyme II (ACE II). Therefore, SARSCoV-2 dissemination can be slowed down by blocking infectious droplets by wearing a mask staying at least 3-6 feet apart, washing and sanitizing hands frequently, and disinfecting indoor air and surfaces frequently. Recent research has demonstrated that SARS-CoV-2 might remain viable on various surfaces, such as glass, countertop surfaces, plastic, doorknobs, cardboard, and stainless steel at least 1224 hours. However, ultraviolet light, such as sunlight will kill the virus within 30 seconds or less and some researchers are looking into this type of therapy which might be beneficial if 
attached to the patient's mechanical ventilation. And while SARS-CoV-2 is likely to remain on contaminated surfaces, research has shown it is not easy to transmit through contaminated surfaces. SARS-CoV-2 RNA has been observed in the urine, stool, and whole blood of COVID-19 patients; however, it is still unknown whether transmission through such mediums is possible. SARS-CoV-2 is spreading across the globe more rapidly than SARS-CoV did [42, 44]. Exposure to infectious droplets, which can remain suspended in the air for long periods of time seems to be the primary mode of transmission.

A meta-analysis of publications was completed, and results showed that gastrointestinal symptoms had been reported in $17.6 \%$ of patients infected with COVID-19 in Hong Kong. Of the stool samples of patients infected with COVID-19, $48.1 \%$ of the stool samples tested positive for shedding of virus RNA. Both caregivers and family need to be careful to avoid the fecal-oral contamination/transmission of the virus. Healthcare workers need to exercise caution during the collection of fecal samples and implementing endoscopic procedures in patients infected with COVID-19-even during the patient's recovery [36]. In addition, pets and zoo animals have tested positive with low levels of SARS-CoV-2 from oral and nasal cavity. For example, in one instance, a patient's dog tested positive around the nasal and oral cavity and showed mild symptoms [40]. In other cases, two tigers and lions from the New York City, USA Zoo also tested positive around the oral and nasal cavities. In Beijing, China, dozens of meat market employees had tested positive after handling raw meat. It was thought that the COVID-19 virus had been active on the packages of meat received at the market. Thousands of meat processing employees in several US states had become infected recently with COVID-19. Beijing government city officials thought the virus had been transmitted by infectious packages, not infectious meat. City officials stopped importing meat for consumption and preparation afterwards and the number of infected individuals has decreased.

A mutation analysis of reported genomes at various locations and times was conducted using bioinformatics programs to disclose the genomic structure and variations of SARS-CoV-2. The genomic signature analysis demonstrated that there is strong relation among the locations of samples, the time of sample collection, and the accumulation of genetic diversity. Mutation may affect the spread and severity of SARSCoV-2. This finding indicates a strong requirement for further inclusive and prompt investigation that combines epidemiological information, genomic details, and graph records of COVID-19 patients' clinical features [45]. US government health experts state that the COVID-19 virus has mutated and is causing a more virulent infection.

Reverse transcription - polymerase chain reaction (RT-PCR) tests have been employed in the COVID-19 diagnosis. The RTPCR testing cycle threshold $\left(C_{t}\right)$ value shows a lot of viral RNA in symptomatic, pre-symptomatic, and asymptomatic residents, which indicates the potential for the disease transmission regardless of symptoms. Symptom-based screening in skilled nursing facilities (SNFs) may fail in identifying around a half of residents infected with COVID-19. Long-term care facilities need to take proactive action to stop the emergence of SARSCoV-2. Symptom ascertainment and room isolation are extremely challenging in elderly residents with neurologic conditions, such as dementia. Once SARS-CoV-2 enters a longterm care SNF, rapid and widespread transmission will probably occur. Once a facility confirms a case of COVID-19, all residents need to be cared for using CDC-recommended personal protective equipment (PPE) with consideration for reuse or a prolonged use of PPE if necessary [46]. Unfortunately for New York City, USA and New Jersey state, USA, governor mandates placing infectious COVID-19 patients back into SNF beds, a lack of adequate PPE in the nursing home, and a lack of adequate training for staff contributed to thousands of COVID19 deaths.

\section{Testing and Diagnosis of COVID-19}

Clinical laboratory analyses and imaging methods have been utilized in the COVID-19 diagnosis, including diagnosis at a laboratory and routine biochemical analysis as well as computerized tomography (CT) and direct lung radiography. Intensive care and mechanical ventilation might be needed during treatment [37]. The routinely used RT-PCR has been a reference method for the diagnosis of COVID-19. For emerging pathogens, real-time RT-PCR is a main diagnostic method. The RT-PCR analysis of COVID-19 provides a considerable opportunity against the COVID-19 pandemic. Some patients might have negative RT-PCR analysis results but positive clinical results. For these cases, the RT-PCR analysis results might become positive in the following days. Thus, clinical results are as important as laboratory results in the diagnosis of COVID-19. False-positive and false-negative cases were reported, especially early during the outbreak of SARS-CoV-2 $[8,37,47]$. Nucleic acid detection using real-time RT-PCR is a standard diagnosis approach that has been broadly used in the clinic; however, the false-positive and false-negative rates of this approach are not neglectable and serological methods are currently needed [48]. An antibody test is available for COVID19; however, the results can sometimes be a false negative. This aspect is concerning, however, there are many institutions that are moving toward antibody tests.

The colloidal gold-based immunochromatographic (ICG) strip targeting viral IgM or IgG antibody was presented and it was compared to real-time RT-PCR. Serological ICG strip assay in diagnosing the SARS-CoV-2 infection is consistent and sensitive. It has been regarded as a good supplementary method in clinical diagnostic applications [48]. A dualfunctional plasmonic biosensor that combines the plasmonic photothermal effect and localized surface plasmon resonance sensing transduction can provide a promising and alternative approach to the clinical diagnosis of COVID-19. In addition, two-dimensional gold nano islands (AuNIs) functionalized with complementary DNA receptors can sensitively detect selected sequences from the novel coronavirus via nucleic acid hybridization [47].

\section{Pharmaceutical Treatment and Comfort Measures}

Scientists proposed three strategies for developing new drugs to fight against coronavirus. Oxygen status is the firstline treatment for the COVID-19 [49]. While some patients can survive with only external oxygen as a strategy for healing, the sicker patients may require mechanical ventilation with a high FiO2. The first strategy was to test existing broad-spectrum antivirals, such as interferons, ribavirin, and cyclophilin inhibitors for treating coronavirus pneumonia. Remdisivir, an antiviral successful for treating other viral diseases, was thought to be one of the first successful therapeutic treatment medications available for COVID-19 and is manufactured by Gilead [50]. However, according to the WHO and the USA Centers for Disease Control (CDC), supportive treatments 
aimed at reducing community spread through social distancing, the use of masks, along with frequent sanitizing and washing hands are the most effective deterrent against the disease. Aggressive isolation measure led to a reduction in cases in European countries and China [49]. Remdesivir, which was approved by the FDA for off-label use of severely ill COVID19 patients, can cause some heart symptoms, including rapid heartbeat, and possibly a heart attack resulting in death. The USA CDC reports that although Remdesivir looked promising, there was never any evidence that it reduced viral load. Another therapy found to be successful by a French scientist is hydroxychloroquine, Zinc, and Zithromax. While this is not an intravenous medication, it must be given early in the course of the disease to cure or prevent the onset of symptoms. However, with the hydroxychloroquine, Zinc, and Zithromax treatment, there has been much controversy with some US physicians and government officials. The WHO stopped its study on hydroxychloroquine when it was evident that severe and possibly fatal heart arrhythmias could occur because of taking this medication. However, hydroxychloroquine was effective at reducing viral load and length of stay among the patients who received it. Some US physicians have indicated that deadly heart arrhythmias and side effects can cause death in the severely ill with this combination of drugs. But some physicians strongly advocate giving the medication trio early in the disease or for mild or severe cases. Within three-five days this therapy seems to work. Hydroxychloroquine is a longstanding medication to treat malaria, lupus, and rheumatoid arthritis. It is important to note that hydroxychloroquine is an anti-inflammatory medication and the combination seemed to work on reducing the length of time spent in the hospital if taken very early in the disease according to a French study. The second was to use available molecular databases to search molecules that might have therapeutic effects on coronavirus. The third was to develop new targeted medicines based on genomic information and pathological features of various coronaviruses, but this procedure may take several years, even 10 years or more $[49,50]$.

Potential therapies for COVID-19 can be classified into two types: a) drugs that affect human cells; b) drugs that affect the human immune system; and c) drugs that target the coronavirus itself. The response of the innate immune system plays a significant role in controlling the coronavirus infection and replication of the virus RNA; interferon, released in response to the virus, is anticipated to boost the immune response by blocking viral replication. Blocking the signal pathways of human cells could be essential for virus replication and might have antiviral effects because the virus often travels inside the cell using the endoplasmic reticulum (ER). Furthermore, viruses often bind to receptor proteins on the cell surface, using active transport to travel into human cells $[50,51]$.

Critical research into vaccines is a race against time as numerous countries are going head to head to find a vaccine by the end of 2020 [50]. At least eight vaccine candidates are already in the third phase of testing in humans and look promising as they have already provided immunity in the test subjects. The pandemic spread of COVID-19 is limited by the development of herd immunity (also called population immunity) or the development of a vaccine. Vaccine development is typically measured in decades however, in this situation, with the COVID-19 pandemic, vaccine development is ongoing in several countries who are simultaneously working on trials. New manufacturing platforms and genomic abilities have increased the likelihood that a vaccine will be discovered with efficacy by December 2020 [52].

Recently, convalescent plasma with the antibodies of those patients previously infected with COVID-19 has shown some efficacy in treating patients severely ill with COVID-19. Therapeutic plasma exchange (TPE) is not a novel treatment and has been used in several diseases. Fresh frozen plasma (FFP) is used as a transmission diluent. The formula for the process of TPE is the total volume of plasma to be replaced calculated by the following: Plasma Replacement = body weight $(\mathrm{kg}) \times(1 / 13) \times(100-$ hematocrit $)$. TPE is performed through a standard femoral central venous catheter (12F) and each patient undergoes a total of five procedures. This therapy is currently being used as adjunctive therapy for severely ill patients $[53,54]$.

There are some drugs against SARS-CoV-2 and they have been subject to limited trials or are under investigation. Remdesivir and hydroxychloroquine have some efficacy against SARS-CoV-2. In the US, Remdesivir is currently only available as an investigative agent or through compassionate use protocols for confirmed SARS-CoV-2 and hospitalized patients with invasive mechanical ventilation. It is unlikely that providers would use this agent in the Emergency Department (ED) at this time. Hydroxychloroquine and Chloroquine are oral medicines that can potentially be used to treat outpatients and people admitted to the hospital [55]. A recent study at the Henry Ford Health System released in June 2020 indicated that hydroxychloroquine is quite efficient at reducing the COVID-19 death rate. In the study, approximately 2,000 patients were included and overall, those given the drug hydroxychloroquine had a significantly lower death rate $(13 \%)$ than those who were given no drugs $(26.4 \%)$. This is a significant finding in COVID-19 treatment. In addition, no patients were found to suffer from cardiac effects by Foxhall Cardiology, including Torsades de Pointes, a potentially fatal tachycardia. While Remdesivir still remains a staple for the treatment of the severely ill and mechanically ventilated patient with COVID-19, there have been no significant findings that this drug is effective at reducing the death rate. However, they may be restricted for COVID-19 indications in the ED until further evidence is available and exceptions are only for very sick patients. As these agents are available in the community, ED clinicians should exercise caution counseling patients who inquire about hydroxychloroquine and chloroquine [55].

A pharmacological approach to the treatment of COVID-19 can be regarded as a two-phase approach. The first phase is regarding viral replication as well as cytopathic effects and antiviral drugs can be considered, such as chloroquinehydroxychloroquine, darunavir ritonavir, lopinavir/ritonavir, and darunavir/cobicistat. The second phase is 7-10 days later starting from the symptom onset and is at the risk of death; the feature at this stage is progressive lung involvement with increasing needs of the oxygen supplementation and ventilatory support. Immunomodulatory and immunosuppressive drugs might help in this phase [56]. There have been asymptomatic COVID-19 patients with normal radiography results. Lopinavir has positive effects on these patients and they may benefit from continuously taking lopinavir. Although arbidol and lopinavir/ritonavir have been administered in clinical practices, their effectiveness on deterring the SARS-CoV-2 replication has not been confirmed. Eosinophil counts have shown the potentiality as a predictor 
Table 2. Stages of psychological intervention

\begin{tabular}{|c|c|c|c|}
\hline \multicolumn{2}{|c|}{ Stages Purposes } & \multirow{2}{*}{$\begin{array}{l}\text { Interventions } \\
\text { 1) Psychoeducation and support to healthcare professionals } \\
\text { in patient management. }\end{array}$} & \multirow{2}{*}{$\begin{array}{l}\begin{array}{l}\text { Professionals to be } \\
\text { Involved }\end{array} \\
\text { 1) Psychologists and } \\
\text { health care professionals }\end{array}$} \\
\hline I & $\begin{array}{l}\text { 1) Containment of the reaction to fear and better } \\
\text { adaptation to the emergency. }\end{array}$ & & \\
\hline & $\begin{array}{l}\text { 2) Reception of a database on the needs of people } \\
\text { in quarantine to develop ad hoc interventions. }\end{array}$ & $\begin{array}{l}\text { 2) Construction and administration of online questionnaires } \\
\text { to detect psychological distress and other symptoms. }\end{array}$ & 2) Psychologists \\
\hline II & $\begin{array}{l}\text { Preventively intercept relevant } \\
\text { psychopathological symptoms and lower } \\
\text { situational stress. }\end{array}$ & $\begin{array}{l}\text { Open online channels of psychological support for } \\
\text { healthcare professionals, caregivers, infection-positive } \\
\text { patients, and general population. }\end{array}$ & $\begin{array}{l}\text { Psychologists and } \\
\text { psychiatrists }\end{array}$ \\
\hline \multirow[t]{2}{*}{$\overline{I I I}$} & $\begin{array}{l}\text { 1) Reduce obsessive/anxious manifestations } \\
\text { (such as thoughts and behaviors), limit health } \\
\text { anxiety, and stabilize mood. }\end{array}$ & $\begin{array}{l}\text { 1) Production and dissemination of psycho-educational } \\
\text { information material for the general population in } \\
\text { quarantine. }\end{array}$ & 1) Psychologists \\
\hline & 2) Prevention of domestic violence crimes. & $\begin{array}{l}\text { 2) Activation of toll-free numbers to support victims of } \\
\text { domestic violence. }\end{array}$ & $\begin{array}{l}\text { 2) Psychologists and } \\
\text { police }\end{array}$ \\
\hline IV & $\begin{array}{l}\text { Reduce the post-traumatic impact of the } \\
\text { emergency (depression, PTSD, substance abuse). }\end{array}$ & $\begin{array}{l}\text { Design and implementation of management interventions } \\
\text { for the psychopathological consequences of the emergency } \\
\text { in health professionals and the general population. }\end{array}$ & $\begin{array}{l}\text { Psychologists and } \\
\text { psychotherapists }\end{array}$ \\
\hline
\end{tabular}

for the progression of COVID-19. Increased eosinophils could be an indicator of improvement in treating COVID-19 [38,57].

A drug-target interaction model that is named Molecule Transformer-Drug Target Interaction (MT-DTI) and based on pre-trained deep learning was utilized to recognize commercially available antiviral drugs for disrupting the viral components of SARS-CoV-2, for example, proteinase, RNAdependent RNA polymerase, and/or helicase. Atazanavir, Kaletra, and Remdesivir have been predicted to obstruct the novel coronavirus. Rapamycin and tiotropium bromide might also work in treating the virus [58].

Certified specific antiviral drugs or vaccines are not available for treating COVID-19. After the COVID-19 outbreak, the State Administration of Traditional Chinese Medicine (TCM) in China organized a professional group to develop a program for treating COVID-19 based on Chinese herbal medicine. The medicine is a mixture of herbs prescribed by herbalists according to patients' various syndromes that are recognized by Chinese diagnostic methods (inquiry, smelling, listening, inspection, and palpation). More than $85 \%$ of COVID-19 patients in China have received TCM treatments. Although TCM has been used in COVID-19, there is still uncertainty in its effectiveness. More clinical research and experiment on TCM should be conducted to further disclose the mechanism of the therapeutic effects of TCM on the treatment of COVID-19 $[7,59]$. The fear of contracting COVID-19 is considerable, which has brought up emotional, psychological, and mental problems due to the pandemic.

\section{Emotional, Psychological, and Mental Impacts of COVID-19}

Medias have led to the psychological and social effects of COVID-19 due to its worldwide outbreak. These effects ranged from neglecting the threat initially to highlighting the virus and the disease later in such a dangerous and distinctive way that anxiety, stress, and even a sense of panic occurred. The COVID19 pandemic has brought up a strong impact on the world with unpredictable psychological consequences. The psychological impact due to quarantines during the spread of COVID-19 is substantial, wide, and probably long term. Increased exposure to social media in the context of lockdowns, quarantine, and isolation increases the tendency to ruminate over information. This outbreak has emphasized the fragility of mental health and the need for the provision of evidence-based interventions to enhance psychological flexibility. When compared with the epidemics of other infectious diseases, fear resulted from COVID-19 is perhaps more considerable and extensive [60].

Quarantine is often characterized by negative emotions, such as frustration, anger, and fear that can result in boredom, anxiety, violence, and/or a feeling of uneasiness. It is appropriate to take actions to plan suitable responses to the psychological crisis due to the COVID-19 health emergency. The phases of psychological interventions are conceptualized and listed in Table 2 [61].

\section{Strategies and Management for Fighting against COVID-19}

The COVID-19 pandemic has become a global problem that forces a need for synergistic collaboration in the world. Based on the principle of One-Health, extending targets of research to the environment and animals with which humans continuously interact helps understand the complicated pandemic better and adopt the most appropriate control procedures. Continuously mapping major epitopes known for viral proteins is an encouraging approach. Defining the map of spreading epitopes among diverse geographical regions and considering various people's habits and the animal population with which the people interact may help provide valuable data or information for building personalized prophylactic and diagnostic strategies [62].

Lessons learned from outbreaks of viral diseases highlight the need for the One Health methodology. The methodology is built on existing capacities, but it is powerful through integrating sectors or disciplines and delivers broader and more health benefits. To increase cross-sector coordination and cooperation promotes science-based decision-making; reduces duplications among sectors related to the health of the environment, humans, and animals; and efficiently deals with outside factors that influence disease burdens. Comparative medicine has been accepted due to its benefits in scientific research. One Health expands the scope of comparative medicine to the surveillance of the environment and animals for risk mitigation and the early detection and better understanding of threats [63].

COVID-19 is continuously causing worldwide economic loss, economic panic, suicides, psychological distress, global fears, and negative impacts on mobility. A One-Health approach is urgently needed to implement a multi-disciplinary method to deal with complicated global health challenges and fully consider human-animal-environment interfaces. One 
Health addresses interrelationships among the environment, humans, and animals; facilitates collaboration; and improves the health of humans and animals (livestock, pets, and wildlife). Teams based on One Health can work together efficiently to find the sources of pathogens and mitigate the threat of virus outbreaks. Global collaborations based on One Health are significant and necessary to fight against COVID-19 [64].

\section{DISCUSSIONS AND CONCLUSION}

COVID-19 has become a global pandemic. Except politics, part of reasons lie in 1) there were many things unknown or not confirmed in the early stage of this disease; 2) many people were not aware of its substantial risk partly due to its some similarities to other viral diseases such as influenza, SARS, MERS, and EVD. These reasons led to the outcome that the disease transmission was not controlled well. COVID-19 has distinct features and novelties compared with influenza, SARS, MERS, and EVD. Although great progress has been made in fighting against COVID-19, there are still considerable challenges because certified specific antiviral drugs or vaccines for treating COVID-19 are still in the development process.

Influenza is an acute infectious disease of viral etiology that has been in global circulation for many decades infecting individuals and causing the death of hundreds of thousands of patients. Over the past 100 years, the world has seen the onset of numerous pandemics, such as the Spanish Flu, H1N1, EBOV, MERS-CoV, and SARS-CoV to name the most common. Treatments have not always been available, and many people have suffered tragic deaths due to these pandemics. However, there has never been a more contagious, more prevalent, and rapidly transmitting viral pandemic than the SARS-CoV-2 or COVID-19. This viral pandemic was transmitted from an unknown origin, likely an animal from a wet market, and has devasted the global population with sickness, death, and the loss of prosperous economies. There has been a struggle to find treatments, models which predict outcomes, vaccines, to slow the transmission of COVID-19. With social distancing (the virus is not known to transmit greater than six feet apart from someone else), the wearing of masks, hand washing and sanitizing, and government mandates from shelter-in-place shutdowns to mandatory methods aimed at reducing the transmission, such as offering fines for not wearing face masks in the USA, etc.

Several diagnostic methods have enhanced the diagnoses of some viral pandemics. For example, HRCT enhances the diagnosis and follow-up of H1N1 virus-associated pneumonia. There have been some biosensors for Influenza A (H1N1) pdm09 detection. The full-length $E$ and $3 a$ proteins are essential for maximal SARS-CoV replication and virulence. MERS-COV can result in an incredibly fatal respiratory infection. EBOV epidemics could continue to recur because some survivors may become carriers.

The transmission of the COVID-19 is much faster than those of SARS and MERS. The genetic analyses suggest that bats are the most probable source of SARS-CoV-2, but further investigation is necessary to confirm this. SARS-CoV-2 spreads mainly through droplet form or respiratory secretion. However, there has been some transmission from fomites, or hard surfaces that have been contaminated with the virus. Fomites range from steel, granite countertops, doorknobs, etc. While cardboard can be a source of transmission, it is difficult for the virus to stick to cardboard, soft surfaces, clothing, or food. While little is known about the viral transmission of COVID-19, studies have shown that sunlight or ultraviolet light will kill the virus on a surface within 30 minutes. Tongues and salivary glands are possible additional hosts of SARS-CoV-2. Many viral RNA in symptomatic, pre-symptomatic, and asymptomatic people indicated the potential for COVID-19 transmission regardless of symptoms. However, respiratory droplets are the dominant method of transmission.

RT-PCR has been a reference method for the COVID-19 diagnosis. Serological ICG strip assay is a good supplementary approach to diagnosing SARS-CoV-2 infection. A dualfunctional plasmonic biosensor that combines the plasmonic photothermal effect and localized surface plasmon resonance sensing transduction is also useful in the diagnosis of COVID19. Two-dimensional gold nanoislands (AuNIs) functionalized with complementary DNA receptors can sensitively detect selected sequences from SARS-CoV-2.

Remdesivir and hydroxychloroquine have some efficacy in fighting SARS-CoV-2. Hydroxychloroquine can potentially be utilized to treat outpatients and people admitted to the hospital. However, while hydroxychloroquine reduces the death rate among patients infected with COVID-19, Remdesivir has not shown to reduce viral load in any patients despite reducing hospital stays. TCM has been used in COVID-19, but further clinical research and experiments should be completed. The fear of contracting COVID-19 is considerable, and the US government is attempting several mandates to reduce transmission, such as mandatory masks, strict social distancing, numerous clinical trials of treatments and vaccines, and shelter-in-place lockdowns. Therefore, the emotional, psychological, physical, psychosocial, and mental impacts of COVID-19 are substantial, wide, and probably cause long term effects. Collaborations in the global world based on One Health are significant to mitigate risks from COVID-19.

Because COVID-19 has become a global pandemic, transparent and open information regarding SARS-CoV-2 and COVID-19, disclosure of their knowledge, and sharing of successful experience or lessons during the pandemic help mitigate the risk of COVID-19 and reduce people's fear due to the pandemic. Due to the rapidity of transmission for this virus, it is imperative that scientists and scholars locate all methods of transmission, any further mitigation actions necessary such as masks, handwashing, and sanitizer, etc.

Future research related to COVID-19 needs to be related to treatment options and vaccines as well as diagnosis, transmission, and the asymptomatic patient. Therefore, future work can be fundamental research in SARS-CoV-2, the mechanism of human-to-human transmission, asymptomatic patients infected with COVID-19 and its transmission mechanism, the development of a vaccine specific for COVID19 , etc. Challenges to researching the COVID-19 pandemic is that there can be many cases in one location of asymptomatic patients who are unidentifiable except by testing. Other challenges include the rapidity associated with patient death and progression for those patients infected with severe cases.

Author contributions: All authors have sufficiently contributed to the study, and agreed with the results and conclusions.

Funding: No funding source is reported for this study.

Declaration of interest: No conflict of interest is declared by authors.

Acknowledgements: Authors thank Technology \& Healthcare Solutions, Mississippi, USA for support. 


\section{REFERENCES}

1. Li SH, Hsieh MJ, Lin SW, Chuang LP, Lee CS, Chiu LC, Chang $\mathrm{CH}$, Hu HC, Huang CC, Kao KC. Outcomes of severe H1N1 pneumoniae: A retrospective study at intensive care units. Journal of the Formosan Medical Association. 2020 Jan 1;119(1):26-33. https://doi.org/10.1016/j.jfma.2019.02.006 PMid:30852002

2. Gralinski LE, Sheahan TP, Morrison TE, Menachery VD, Jensen K, Leist SR, Whitmore A, Heise MT, Baric RS. Complement activation contributes to severe acute respiratory syndrome coronavirus pathogenesis. MBio. 2018 Nov 7;9(5):e01753-18. https://doi.org/10.1128/ mBio.01753-18 PMid:30301856 PMCid:PMC6178621

3. Hou YA, Tan YR, Lim WY, Lee V, Tan LW, Mark I, Chen C, Yap P. Adequacy of public health communications on H7N9 and MERS in Singapore: insights from a community based cross-sectional study. BMC public health. 2018 Dec;18(1):436. https://doi.org/10.1186/s12889-018-5340-x PMid:29609573 PMCid:PMC5879609

4. Balelli I, Pasin C, Prague M, Crauste F, Van Effelterre T, Bockstal V, Solforosi L, Thiébaut R. A model for establishment, maintenance and reactivation of the immune response after vaccination against Ebola virus. Journal of Theoretical Biology. 2020 Mar 21:110254. https://doi.org/10.1016/j.jtbi.2020.110254 PMid:32205143

5. Durham ND, Howard AR, Govindan R, Senjobe F, Fels JM, Diehl WE, Luban J, Chandran K, Munro JB. Real-Time Analysis of Individual Ebola Virus Glycoproteins Reveals Pre-Fusion, Entry-Relevant Conformational Dynamics. Viruses. 2020 Jan;12(1):103. https://doi.org/10.3390/ v12010103 PMid:31952255 PMCid:PMC7019799

6. Rojek AM, Horby PW. Modernising epidemic science: enabling patient-centred research during epidemics. BMC medicine. 2016 Dec 1;14(1):212. https://doi.org/10.1186/ s12916-016-0760 PMid:27989237 PMCid:PMC5165716

7. Yang Y, Islam MS, Wang J, Li Y, Chen X. Traditional Chinese medicine in the treatment of patients infected with 2019new coronavirus (SARS-CoV-2): a review and perspective. International journal of biological sciences. 2020;16(10):1708. https://doi.org/10.7150/ijbs.45538 PMid:32226288 PMCid:PMC7098036

8. Seo G, Lee G, Kim MJ, Baek SH, Choi M, Ku KB, Lee CS, Jun S, Park D, Kim HG, Kim SJ. Rapid detection of COVID-19 causative virus (SARS-CoV-2) in human nasopharyngeal swab specimens using field-effect transistor-based biosensor. ACS nano. 2020 Apr 15. https://doi.org/10.1021/ acsnano.0c02823 PMid:32293168 PMCid:PMC7172500

9. Porcheddu R, Serra C, Kelvin D, Kelvin N, Rubino S. Similarity in case fatality rates (CFR) of COVID-19/SARSCOV-2 in Italy and China. The Journal of Infection in Developing Countries. 2020 Feb 29;14(02):125-8. https://doi.org/10.3855/jidc.12600 PMid:32146445

10. Zhang S, Diao M, Yu W, Pei L, Lin Z, Chen D. Estimation of the reproductive number of novel coronavirus (COVID-19) and the probable outbreak size on the Diamond Princess cruise ship: A data-driven analysis. International Journal of Infectious Diseases. 2020 Apr 1;93:201-4. https://doi.org/10.1016/j.ijid.2020.02.033 PMid:32097725 PMCid:PMC7110591
11. Nassar AH, Zern NK, Mclntyre LK, Lynge D, Smith CA, Petersen RP, Horvath KD, Wood DE. Emergency restructuring of a general surgery residency program during the coronavirus disease 2019 pandemic: the university of Washington experience. JAMA surgery. 2020 Apr 6. https://doi.org/10.1001/jamasurg.2020.1219 PMid:32250417

12. de Hoog ML, Venekamp RP, Meijer A, Sanders EA, BruijningVerhagen PC. Inactivated influenza vaccine does not reduce all cause respiratory illness in children with preexisting medical conditions. Vaccine. 2019 Dec 16. https://doi.org/10.1016/j.vaccine.2019.11.086 PMid:31859200

13. Tuckerman J, Crawford NW, Marshall HS. Disparities in parental awareness of children's seasonal influenza vaccination recommendations and influencers of vaccination. PloS one. 2020 Apr 9;15(4):e0230425. https://doi.org/10.1371/journal.pone.0230425 PMid:32271793 PMCid:PMC7145195

14. Mastalerz-Migas A, Kuchar E, Nitsch-Osuch A, Mamcarz A, Sybilski A, Wełnicki M, Duda-Król W, Antczak A. Recommendations for the prevention, diagnosis and treatment of inFLUenza in adults for Primary care physiciAnS: FLU COMPAS PCP-ADULTS. Family Medicine \& Primary Care Review.;22(1):81-96. https://doi.org/10.5114/ fmpcr.2020.90629

15. Singh DE, Marinescu MC, Carretero J, Delgado-Sanz C, Gomez-Barroso D, Larrauri A. Evaluating the impact of the weather conditions on the influenza propagation. BMC Infectious Diseases. 2020 Dec;20:1-4. https://doi.org/ 10.1186/s12879-020-04977-w PMid:32248792 PMCid: PMC7132999

16. Fontes CA, dos Santos AA, de Oliveira SA. High-resolution computed tomography enhances the diagnosis and followup of influenza A (H1N1) virus-associated pneumonia. The Journal of Infection in Developing Countries. 2020 Mar 31;14(03):317-20. https://doi.org/10.3855/jidc.11665 PMid:32235094

17. Dalal A, Mohan H, Prasad M, Pundir CS. Detection methods for influenza A H1N1 virus with special reference to biosensors: a review. Bioscience reports. 2020 Feb;40(2):BSR20193852. https://doi.org/10.1042/ BSR20193852 PMid:32016385 PMCid:PMC7000365

18. Schoen K, Horvat N, Guerreiro NF, de Castro I, de Giassi KS. Spectrum of clinical and radiographic findings in patients with diagnosis of $\mathrm{H} 1 \mathrm{~N} 1$ and correlation with clinical severity. BMC infectious diseases. 2019 Dec;19(1):1-8. https://doi.org/10.1186/s12879-019-4592-0 PMid:31718571 PMCid:PMC6852716

19. Schoeman D, Fielding BC. Coronavirus envelope protein: current knowledge. Virology journal. 2019 Dec;16(1):69. https://doi.org/10.1186/s12985-019-1182-0 PMid:31133031 PMCid:PMC6537279

20. Abdirizak F, Lewis R, Chowell G. Evaluating the potential impact of targeted vaccination strategies against severe acute respiratory syndrome coronavirus (SARS-CoV) and Middle East respiratory syndrome coronavirus (MERS-CoV) outbreaks in the healthcare setting. Theoretical Biology and Medical Modelling. 2019 Dec 1;16(1):16. https://doi.org/10.1186/s12976-019-0112-6 PMid:31587665 PMCid:PMC6778978 
21. Zhang P, Li J, Liu H, Han N, Ju J, Kou Y, Chen L, Jiang M, Pan $F$, Zheng Y, Gao Z. Long-term bone and lung consequences associated with hospital-acquired severe acute respiratory syndrome: a 15-year follow-up from a prospective cohort study. Bone Research. 2020 Feb 14;8(1):1-8. https://doi.org/10.1038/s41413-020-0084-5 PMid:32128276 PMCid:PMC7018717

22. Castaño-Rodriguez C, Honrubia JM, Gutiérrez-Álvarez J, DeDiego ML, Nieto-Torres JL, Jimenez-Guardeño JM, Regla-Nava JA, Fernandez-Delgado R, Verdia-Báguena C, Queralt-Martín M, Kochan G. Role of severe acute respiratory syndrome coronavirus viroporins $\mathrm{E}, 3 \mathrm{a}$, and $8 \mathrm{a}$ in replication and pathogenesis. MBio. $2018 \mathrm{Jul}$ 5;9(3):e02325-17. https://doi.org/10.1128/mBio.02325-17 PMid:29789363 PMCid:PMC5964350

23. Ul Qamar MT, Saleem S, Ashfaq UA, Bari A, Anwar F, Alqahtani S. Epitope - based peptide vaccine design and target site depiction against Middle East Respiratory Syndrome Coronavirus: an immune-informatics study. Journal of translational medicine. 2019 Dec 1;17(1):362. https://doi.org/10.1186/s12967-019-2116-8 PMid:31703698 PMCid:PMC6839065

24. Bleibtreu A, Bertine M, Bertin C, Houhou-Fidouh N, Visseaux B. Focus on Middle East respiratory syndrome coronavirus (MERS-CoV). Medecine et maladies infectieuses. 2019 Nov 11. https://doi.org/10.1016/j.medmal.2019.10.004 PMid: 31727466 PMCid:PMC7125975

25. Albarrak Al, Mohammed R, Al Elayan A, Al Fawaz F, Al Masry M, Al Shammari M, Miaygil SB. Middle East Respiratory Syndrome (MERS): Comparing the knowledge, attitude and practices of different health care workers. Journal of Infection and Public Health. 2019 Aug 17. https://doi.org/ 10.1016/j.jiph.2019.06.029 PMCid:PMC7102554

26. Killerby ME, Biggs HM, Midgley CM, Gerber SI, Watson JT. Middle East respiratory syndrome coronavirus transmission. Emerging infectious diseases. 2020 Feb;26(2):191. https://doi.org/10.3201/eid2602.190697 PMid:31961300 PMCid:PMC6986839

27. Paolone S. Extracorporeal membrane oxygenation (ECMO) for lung injury in severe acute respiratory distress syndrome (ARDS): review of the literature. Clinical nursing research. 2017 Dec;26(6):747-62. https://doi.org/10.1177/ 1054773816677808 PMid:27836935

28. Franchineau G, Bréchot N, Hékimian G, Lebreton G, Bourcier S, Demondion P, Le Guennec L, Nieszkowska A, Luyt CE, Combes A, Schmidt M. Prone positioning monitored by electrical impedance tomography in patients with severe acute respiratory distress syndrome on venovenous ECMO. Annals of intensive care. 2020 Dec 1;10(1):12. https://doi.org/10.1186/s13613-020-0633-5 PMid:32016593 PMCid:PMC6997307

29. Sanchez E, Price DR, Chung KP, Oromendia C, Choi AM, Schenck EJ, Siempos II. Persistent severe acute respiratory distress syndrome for the prognostic enrichment of trials. PloS one. 2020 Jan 27;15(1):e0227346. https://doi.org/ 10.1371/journal.pone.0227346 PMid:31986174 PMCid: PMC6984692

30. Aceng JR, Ario AR, Muruta AN, Makumbi I, Nanyunja M, Komakech I, Bakainaga AN, Talisuna AO, Mwesigye C, Mpairwe AM, Tusiime JB. Uganda's experience in Ebola virus disease outbreak preparedness, 2018-2019. Globalization and Health. 2020 Dec;16(1):1-2. https://doi.org/10.1186/s12992-020-00548-5 PMid:32192540 PMCid:PMC7081536
31. Couturier C, Wada A, Louis K, Mistretta M, Beitz B, Povogui M, Ripaux M, Mignon C, Werle B, Lugari A, Pannetier D. Characterization and analytical validation of a new antigenic rapid diagnostic test for Ebola virus disease detection. PLOS Neglected Tropical Diseases. 2020 Jan 17;14(1):e0007965. https://doi.org/10.1371/journal.pntd. 0007965 PMid:31951615 PMCid:PMC6992227

32. Matson MJ, Chertow DS, Munster VJ. Delayed recognition of Ebola virus disease is associated with longer and larger outbreaks. Emerging Microbes \& Infections. 2020 Jan 1;9(1):291-301. https://doi.org/10.1080/22221751.2020. 1722036 PMid:32013784 PMCid:PMC7034085

33. Rojas M, Monsalve DM, Pacheco Y, Acosta-Ampudia $\mathrm{Y}$, Ramírez-Santana C, Ansari AA, Gershwin ME, Anaya JM. Ebola virus disease: An emerging and re-emerging viral threat. Journal of autoimmunity. 2020 Jan 1;106:102375. https://doi.org/10.1016/j.jaut.2019.102375 PMid:31806422

34. Fuentes S, Ravichandran S, Coyle EM, Klenow L, Khurana S. Human antibody repertoire following Ebola virus infection and vaccination. Iscience. 2020 Mar 27;23(3):100920. https://doi.org/10.1016/j.isci.2020.100920 PMid:32145646 PMCid:PMC7058406

35. Li JW, Han TW, Woodward M, Anderson CS, Zhou H, Chen YD, Neal B. The impact of 2019 novel coronavirus on heart injury: A systemic review and Meta-analysis. Progress in Cardiovascular Diseases. 2020 Apr 16. https://doi.org/ 10.1016/j.pcad.2020.04.008 PMCid:PMC7160645

36. Cheung KS, Hung IF, Chan PP, Lung KC, Tso E, Liu R, Ng YY, Chu MY, Chung TW, Tam AR, Yip CC. Gastrointestinal manifestations of SARS-CoV-2 infection and virus load in fecal samples from the Hong Kong cohort and systematic review and meta-analysis. Gastroenterology. 2020 Apr 3. https://doi.org/10.1053/j.gastro.2020.03.065 PMid:32251668 PMCid:PMC7194936

37. Cakir Z, Savas HB. A Mathematical Modelling Approach in the Spread of the Novel 2019 Coronavirus SARS-CoV-2 (COVID-19) Pandemic. Electron J Gen Med. 2020; 17 (4): em205. https://doi.org/10.29333/ejgm/7861

38. Xu T, Chen C, Zhu Z, Cui M, Chen C, Dai H, Xue Y. Clinical features and dynamics of viral load in imported and nonimported patients with COVID-19. International Journal of Infectious Diseases. 2020 Mar 14. https://doi.org/ 10.1016/j.ijid.2020.03.022 PMid:32179140 PMCid: PMC7270709

39. Dawood AA. Mutated COVID-19, May Foretells Mankind in a Great Risk in the Future. New Microbes and New Infections. 2020 Apr 4:100673. https://doi.org/10.1016/ j.ijid.2020.03.020 PMid:32179137 PMCid:PMC7270890

40. Law S, Leung AW, Xu C. Severe acute respiratory syndrome (SARS) and coronavirus disease-2019 (COVID-19): From causes to preventions in Hong Kong. International Journal of Infectious Diseases. 2020 Apr 3. https://doi.org/ 10.1016/j.ijid.2020.03.059 PMid:32251790 PMCid: PMC7195109

41. Decaro N, Lorusso A. Novel human coronavirus (SARS-CoV2): a lesson from animal coronaviruses. Veterinary Microbiology. 2020 Apr 14:108693. https://doi.org/10.1016/ j.vetmic.2020.108693 PMid:32402329 PMCid:PMC7195271

42. Park SE. Epidemiology, virology, and clinical features of severe acute respiratory syndrome-coronavirus-2 (SARSCoV-2; Coronavirus Disease-19). Clinical and Experimental Pediatrics. 2020 Apr;63(4):119. https://doi.org/10.3345/ cep.2020.00493 PMid:32252141 PMCid:PMC7170784 
43. Malik YS, Sircar S, Bhat S, Sharun K, Dhama K, Dadar M, Tiwari R, Chaicumpa W. Emerging novel coronavirus (2019$\mathrm{nCoV}$ )-current scenario, evolutionary perspective based on genome analysis and recent developments. Veterinary quarterly. 2020 Jan 1;40(1):68-76. https://doi.org/10.1080/ 01652176.2020.1727993 PMid:32036774 PMCid: PMC7054940

44. Xu R, Cui B, Duan X, Zhang P, Zhou X, Yuan Q. Saliva: potential diagnostic value and transmission of 2019-nCoV. International Journal of Oral Science. 2020 Apr 17;12(1):16. https://doi.org/10.1038/s41368-020-0080-z PMid: 32300101 PMCid:PMC7162686

45. Khailany RA, Safdar M, Ozaslan M. Genomic characterization of a novel SARS-CoV-2. Gene Reports. 2020 Apr 16:100682. https://doi.org/10.1016/j.genrep.2020. 100682 PMid:32300673 PMCid:PMC7161481

46. Kimball A. Asymptomatic and presymptomatic SARS-CoV-2 infections in residents of a long-term care skilled nursing facility-King County, Washington, March 2020. MMWR. Morbidity and mortality weekly report. 2020;69. https://doi.org/10.15585/mmwr.mm6913e1 PMid:32240128 PMCid:PMC7119514

47. Qiu G, Gai Z, Tao Y, Schmitt J, Kullak-Ublick GA, Wang J. Dual-functional plasmonic photothermal biosensors for highly accurate severe acute respiratory syndrome coronavirus 2 detection. ACS nano. 2020 Apr 13. https://doi.org/10.1021/acsnano.0c02439 PMid:32281785 PMCid:PMC7158889

48. Pan Y, Li X, Yang G, Fan J, Tang Y, Zhao J, Long X, Guo S, Zhao Z, Liu Y, Hu H. Serological immunochromatographic approach in diagnosis with SARS-CoV-2 infected COVID-19 patients. Journal of Infection. 2020 Apr 10. https://doi.org/10.1016/j.jinf.2020.03.051 PMid:32283141 PMCid:PMC7195339

49. Cascella M, Rajnik M, Cuomo A, Dulebohn SC, Di Napoli R. Features, evaluation and treatment coronavirus (COVID19). InStatpearls [internet] 2020 Mar 8. StatPearls Publishing. https://www.ncbi.nlm.nih.gov/books/ NBK554776/ PMid:32150360

50. Wu C, Liu Y, Yang Y, Zhang P, Zhong W, Wang Y, Wang Q, Xu Y, Li M, Li X, Zheng M. Analysis of therapeutic targets for SARS-CoV-2 and discovery of potential drugs by computational methods. Acta Pharmaceutica Sinica B. 2020 Feb 27. https://doi.org/10.1016/j.apsb.2020.02.008 PMid:32292689 PMCid:PMC7102550

51. Inoue T, Tsai B. How viruses use the endoplasmic reticulum for entry, replication, and assembly. Cold Spring Harbor perspectives in biology. 2013 Jan 1;5(1):a013250. https://doi.org/10.1101/cshperspect.a013250

PMid:23284050 PMCid:PMC3579393

52. Graham BS. Rapid COVID-19 vaccine development. Science. $2020 \quad$ May 29;368(6494):945-946. https://doi.org/10.1126/science.abb8923 PMid:32385100

53. Khamis F, Al-Zakwani I, Al Hashmi S, Al Dowaiki S, Al Bahrani M, Pandak N, Al Khalili H, Memish Z. Therapeutic Plasma Exchange in Adults with Severe COVID-19 Infection. International Journal of Infectious Diseases. 2020 Jun 23. https://doi.org/10.1016/j.ijid.2020.06.064 PMid:32585284

54. Keith P, Day M, Perkins L, Moyer L, Hewitt K, Wells A. A novel treatment approach to the novel coronavirus: an argument for the use of therapeutic plasma exchange for fulminant COVID-19. 2020: 1-3. https://doi.org/10.1186/s13054-0202836-4 PMid:32241301 PMCid:PMC7117947
55. Brown C, Noble J, Coralic Z. Brief Summary of Potential SARS-CoV-2 Prophylactic and Treatment Drugs in the Emergency Department. Western Journal of Emergency Medicine: Integrating Emergency Care with Population Health. 2020 Mar 31. https://doi.org/10.5811/ westjem.2020.3.47328 PMid:32302280 PMCid:PMC7234712

56. Alberici F, Delbarba E, Manenti C, Econimo L, Valerio F, Pola A, Maffei C, Possenti S, Piva S, Latronico N, Focà E. Management of patients on dialysis and with kidney transplant during SARS-COV-2 (COVID-19) pandemic in Brescia, Italy. Kidney International Reports. 2020 Apr 4. https://doi.org/10.1016/j.ekir.2020.04.001 PMid:32292866 PMCid:PMC7128395

57. Liu F, Xu A, Zhang Y, Xuan W, Yan T, Pan K, Yu W, Zhang J. Patients of COVID-19 may benefit from sustained lopinavircombined regimen and the increase of eosinophil may predict the outcome of COVID-19 progression. International Journal of Infectious Diseases. 2020 Mar 12. https://doi.org/10.1016/j.ijid.2020.03.013 PMid:32173576 PMCid:PMC7193136

58. Beck BR, Shin B, Choi Y, Park S, Kang K. Predicting commercially available antiviral drugs that may act on the novel coronavirus (SARS-CoV-2) through a drug-target interaction deep learning model. Computational and structural biotechnology journal. 2020 Mar 30. https://doi.org/10.1016/j.csbj.2020.03.025 PMid:32280433 PMCid:PMC7118541

59. Li Y, Liu X, Guo L, Li J, Zhong D, Zhang Y, Clarke M, Jin R. Traditional Chinese herbal medicine for treating novel coronavirus (COVID-19) pneumonia: protocol for a systematic review and meta-analysis. Systematic reviews. 2020 Dec;9:1-6. https://doi.org/10.1186/s13643-020-013434 PMid:32268923 PMCid:PMC7138957

60. Presti G, Mchugh L, Gloster A, Karekla M, Hayes SC. The dynamics of fear at the time of COVID-19: a contextual behavioral science perspective. Clinical Neuropsychiatry. 2020 Apr 1;17(2). https://doi.org/10.36131/CN20200206

61. Orrù G, Ciacchini R, Gemignani $A$, Conversano $C$. Psychological intervention measures during the COVID-19 pandemic. Clinical Neuropsychiatry. 2020 Jan 1;17(2):76-9. https://doi.org/10.36131/CN20200208

62. Tilocca B, Soggiu A, Sanguinetti M, Musella V, Britti D, Bonizzi L, Urbani A, Roncada P. Comparative computational analysis of SARS-CoV-2 nucleocapsid protein epitopes in taxonomically related coronaviruses. Microbes and infection. 2020 Apr 14. https://doi.org/10.1016/j.micinf.2020.04.002 PMid:32302675 PMCid:PMC7156246

63. Kelly TR, Machalaba C, Karesh WB, Crook PZ, Gilardi K, Nziza J, Uhart MM, Robles EA, Saylors K, Joly DO, Monagin C. Implementing One Health approaches to confront emerging and re-emerging zoonotic disease threats: lessons from PREDICT. One Health Outlook. 2020 Dec;2(1):1-7. https://doi.org/10.1186/s42522-019-0007-9 PMCid:PMC7149069

64. El Zowalaty ME, Järhult JD. From SARS to COVID-19: A previously unknown SARS-CoV-2 virus of pandemic potential infecting humans-Call for a One Health approach. One Health. 2020 Feb 24:100124. https://doi.org/10.1016/j.onehlt.2020.100124 PMid:32195311 PMCid:PMC70759 